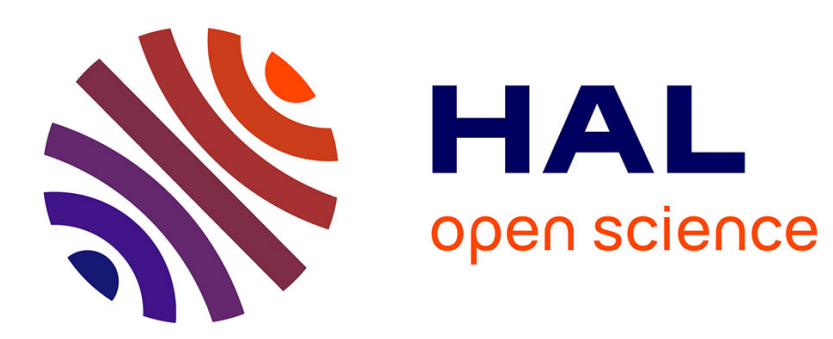

\title{
Decision over Time as a By-Product of a Measure of Utility: A Reappraisal of Paul Samuelson's "A Note on Measurement of Utility" (1937)
}

Amélie Fievet

\section{- To cite this version:}

Amélie Fievet. Decision over Time as a By-Product of a Measure of Utility: A Reappraisal of Paul Samuelson's "A Note on Measurement of Utility" (1937). European Journal of the History of Economic Thought, In press. halshs-03453458

\section{HAL Id: halshs-03453458 \\ https://shs.hal.science/halshs-03453458}

Submitted on 28 Nov 2021

HAL is a multi-disciplinary open access archive for the deposit and dissemination of scientific research documents, whether they are published or not. The documents may come from teaching and research institutions in France or abroad, or from public or private research centers.
L'archive ouverte pluridisciplinaire HAL, est destinée au dépôt et à la diffusion de documents scientifiques de niveau recherche, publiés ou non, émanant des établissements d'enseignement et de recherche français ou étrangers, des laboratoires publics ou privés. 


\title{
Decision over Time as a By-Product of a Measure of Utility: A Reappraisal of Paul Samuelson's “A Note on Measurement of Utility" (1937)
}

Amélie Fievet ${ }^{1}$

September 2021

\begin{abstract}
This contribution aims to highlight a neglected aspect of Samuelson's famous 1937 paper "A Note on Measurement of Utility". Although the 1937 paper is usually regarded as the foundation of discounted utility theory, and rightly so, it is primarily concerned with utility measurement and deals only indirectly with decision over time - intertemporal issues appearing as a by-product of the realisation of a unique utility measure. But the treatment of discounted utility in turn influenced Samuelson's understanding of cardinality. Cardinality appears here as the result of a cognitive ability that manifests when agents face a decision experiment over time in which they are compelled to cardinalize their utility functions. The result is the weak plausibility of cardinality in a more general context, such that, contrary to the usual views, we may say that Samuelson's ordinalist approach was already in the making in 1937.
\end{abstract}

Keywords: Paul Samuelson, discounted utility, measure of utility.

JEL classification: B21, B31, D01, D90, D15.

\section{Introduction}

Scholars engaged in both analytical and historical work regarding utility over time are united in seeing modern discounted utility theory as having been founded by Paul Samuelson in his 1937 article "A Note on Measurement of Utility". However, although it is clear that Samuelson there constructed a procedure that accounts for the way agents make decisions over time, this was not the main focus of his paper: from its title alone, it is easy to see that it concerns the measurement of utility. It aimed at measuring utility in a cardinal way - that is, in the vocabulary of the thirties, in a unique way (in the sense of

\footnotetext{
${ }^{1}$ PHARE, University Paris 1 Panthéon-Sorbonne - 106-112, boulevard de l'Hôpital - 75647 Paris
}

Cedex 13 - France. E-mail: amelie-martine-anne-marie.fievet@univ-paris1.fr. 
what we call today an "interval scale", see Stevens, 1946). Samuelson's paper shows that intertemporal utility only appears as a by-product of achieving a unique utility measure. The present article therefore lays out how, in seeking to construct a method for the measurement of utility, Samuelson moved from utility analysis to intertemporal utility analysis, and describes the implications of his doing so. This juncture between discounted utility and the measurement of utility has not received much attention. In analytical works it is usually neglected, the focus falling instead either on discounted utility (Loewenstein and Prelec, 1992; Shefrin, 1998; Frederick, Loewenstein and O'Donoghue, 2002; Manzini and Mariotti, 2009) or the measurement of utility - where the latter is understood as the cardinal measure of utility. In relation to the latter, authors have long treated Samuelson as a source for quotations - consider for example Frederik Zeuthen (1937), Daniel Ellsberg (1954), and Marek Hudik (2014) - but only Zeuthen (1937) actually refers to Samuelson's 1937 article. Of course, other contributions which deal with the measurement of utility might also be considered relevant to this paper, such as those of William Vickrey (1945) and Armen A. Alchian (1953), although they do not mention Samuelson. A similar divergence of focus can be observed among historical studies, although they tend to give a more qualified account (Ellingsen, 1994; Loewe, 2006; Moscati, 2013; Backhouse, 2017).

The work of German Loewe (2006) provides an example of these more nuanced historical approaches. Pointing out that Samuelson solved his problem of measuring the utility of income by using a specific discount function that describes individuals' preferences over time regarding their income, Loewe (2006, p. 201) goes on to observe that Samuelson assumed that people discount future amounts using an exponential factor. This procedure is a means of making utilities from different dates comparable, in continuity with the first generations of utilitarians in the $18^{\text {th }}$ and $19^{\text {th }}$ centuries (from Bentham to John Stuart Mill, Jevons, Edgeworth and Sidgwick). In hindsight, therefore, Samuelson's project can be viewed as part of an age-old debate on the possibility of obtaining a cardinal measure of utility, to the extent that Tore Ellingsen (1994, p. 126) could rightly credit Samuelson for the early recognition of cardinal utility conditions (although the phrase itself is not used by Samuelson). Similarly, Ivan Moscati (2013, p. 927) argued that in the 1937 article, individuals maximize an intertemporal utility 
function that represents the sum of all future discounted utilities, pointing out that this implies they have an ability to compare ratios of differences.

This paper builds on these historical contributions, arguing, however, that Samuelson's particular treatment of the relation between the decision in time and the measurement of utility meant that neither could be considered in isolation from the other. As historians of economic thought have already noted, what Samuelson said about discounted utility cannot be accounted for without explicit reference to his project of measuring utility. Symmetrically (and I would like to stress this point), what he said about measuring utility, and specifically his understanding of cardinal utility, is shaped by what he said about discounted utility. Cardinality thus seems to be only an effect of a methodological step in which choices in time were involved. And so, although Samuelson's 1937 paper is one of the rare contributions in which he does not favour the ordinalism he was to adopt in later works, his cardinalism rests on cognitive prerequisites that he himself found so implausible that they could not deflect him from what was to become his ordinalist stance. ${ }^{2}$ It is therefore difficult to interpret this paper as an effect of Samuelson's alleged methodological shift between utilitarianism and behaviourism (as argued by Moscati, 2013, p. 932): indeed, there is no evidence of a methodological shift or of any "scientific opportunism" (ibid.). So we have no reason to infer that there was a change in Samuelson's position after 1937: his own doubts about the cognitive basis of the obviously limited procedure he had constructed in 1937 show that, despite his compelled cardinalism at that time, his position could already be considered ordinalist.

The first objective of this paper is to show that Samuelson's aim in 1937 was, in fact, to determine the unique measure of utility, and not to establish the foundations of discounted utility theory. Although in the latter respect he was indeed successful, it will be shown that such a theory is actually an indirect result, since his theory of intertemporal utility is only a step in the direction of measuring utility (Section 2).

\footnotetext{
${ }^{2}$ We could mention here Samuelson's later acceptance of expected utility theory, i.e. his acceptance of cardinal utility functions that refer to the decision in risk. However, the cardinality resulting from the decision in risk does not have the same cognitive implications as the cardinality that refers, as discussed here, to the desirability of goods. The former does not reflect the intensity of preferences but an attitude towards risk. These two types of cardinality therefore do not have the same status.
} 
It should be obvious that this instrumental role played by discounted utility has an influence not only on the formal procedure leading to the determination of cardinal utility, but also on the way it should be understood (Section 3). Whereas uniqueness was defined in association with positive affine transformations, Samuelson was clearly not at ease with the idea of cardinality, in which he saw an arbitrary assumption about the behaviour of agents. If cardinality made sense, it was only as a cognitive requirement embedded in the procedure that he would then build, a procedure in which the agents are compelled to cardinalize their function of utility. Cardinality is compelled, i.e. it stems from the structure of decision in time. There is no question of cardinality when we take instantaneous decisions: it is only the framework of decision in time which forces us to adopt some cardinality. This way of understanding the relation between cardinality and decision in time is quite different from the one with which we are today familiar: whereas for Samuelson the instantaneous utility function remains invariant when the preference for the present changes (which only affects our discount rate), we would today consider that the same preferences over time could be represented by a family of different instantaneous utility functions associated with different discount rates (see Fishburn and Rubinstein, 1982).

\section{The measurement of utility: from utility to intertemporal utility}

Samuelson's papers of his subsequent career are usually rooted in ongoing debates whose protagonists are clearly marked; this early paper, however, cites very few authors on the issue of utility measurement, despite the fact that this was already an important debate at the time. He mentions only Irving Fisher (1927) and Ragnar Frisch (1932) for their use of an indirect method of measurement based on budget constraints (Samuelson, 1937, p. 155, n. 1), and it is only at the end of the article that reference is made to Oskar Lange (1934) concerning the possibility of ordering utility differences (Samuelson, 1937, p. 161, n. 1). It may seem surprising that Samuelson relied on such a small number of references in 1937, whereas other contributions that would have been known to him had also 
addressed the question of utility measurement. ${ }^{3}$ As already noted by Roger E. Backhouse (2017, p. 643) on the basis of a fragmentary note, the explanation seems to be a methodological choice: according to Backhouse, Samuelson did not view himself as offering anything completely new, which meant that he did not find it necessary to read and quote everything written on the subject he was dealing with. However, although indeed not completely new, his choice of a mathematical presentation did lend his account a universality which was lacking elsewhere at the time; nevertheless, for the contemporary reader, Samuelson's paper is to be considered within the context of the debates and questions to which he aimed at giving a final response.

\subsection{The quest for a measure of utility: what was at stake?}

In Samuelson's view, the various existing methods of measuring utility gave a rather weak answer: they paved the way only for what would later be called an "ordinal measure", ${ }^{4}$ which only allowed a ranking of the utilities of different baskets of goods. The result was the construction of indifference curves. But Samuelson's goal in 1937 was more demanding. His purpose was to build a procedure which allows a complete specification of a cardinal utility function:

The possibility of measuring the marginal utility of income from budgetary studies and market behaviour has been investigated by many writers. [...] As has long been known, the behaviour of an individual in the market, when confronted with various price combinations and under limitations of various incomes, is not in itself sufficient to determine the form of his utility function [the full specification of a cardinal utility function], but can only give us at best a system of indifference loci to which an infinite number of utility indexes might have given rise. [...] In this note, a possible alternative method, resting upon different assumptions, is presented, not so much in the hope of furthering inductive investigation in these

\footnotetext{
${ }^{3}$ For instance, Samuelson did not mention the contributions of Harro Bernardelli (1934), Ernest H. Phelps Brown (1934), or Roy G. D. Allen (1935); although by contrast he referred to all of them the following year (Samuelson, 1938b). Above all, Franz Alt's 1936 paper should have been particularly useful, since it is based on an axiomatic approach. Although Lange drew his attention to it, it seems that Samuelson did not really read it (see Moscati, 2019, pp. 112-113). If he had, he would have found in Alt an approach rather similar to his own.

${ }^{4}$ It seems that the terms "ordinal" and "cardinal" first appeared in their usual sense in a paper by John Hicks and Roy G. D. Allen (1934). Samuelson did not use them in his 1937 paper, although he used them extensively in his 1938b. The issue of the difference between ordinal and cardinal measures is dealt with infra, section 3, p. 13.
} 
matters as of bringing out certain theoretical relations between the variables under consideration. (Samuelson, 1937, p. 155)

Indeed, the method of measuring utility that had hitherto been subject to consensus does not explain anything about the magnitude of the change of utility when moving from one utility curve to another. Accounting for this change would give what Samuelson called a "unique measure of utility" (Samuelson, 1937, p. 155, n. 2), as opposed to simply plotting indifference curves. Although the objective was clear, the means to reach it were not:

To arrive at a unique measure of utility certain extra assumptions must be made in order to select a particular scale out of the infinitude of possible scales. (Samuelson, 1937, p. 155, n. 2)

Samuelson's achievement in 1937 was to develop what could be considered a two-step theoretical trick. The first step is a direct consequence of the fact that we only have indifference curves: shifting from one curve to another implies successive (and, therefore, in time) variations of income. Samuelson's first step was thus to consider income variations and, through them, the induced utility variations:

Under the following [...] assumptions, it is believed possible to arrive theoretically at a precise measure of the marginal utility of money income to an individual whose tastes maintain a certain invariance [with respect to the instantaneous consumption of goods] throughout the time under consideration, and during which time the prices of all goods remain constant. (Samuelson, 1937, p. 155)

A unique measure requires something more, however, and the second step is far from obvious. In order to base his method on potentially observable behaviours, Samuelson imagined variations in income over time. It is this latter complication that imposed an additional constraint on the form of the income utility function, making it cardinal. If his 1937 article deals with decision over time, therefore, it is only instrumentally, i.e. as a means of obtaining a cardinal measure of utility on an experimental basis. Samuelson's procedure thus makes it possible to describe the preferences of the individuals as well as their intensities (that is, to handle subjective information) on the basis of experimental data, namely the allocation of income expenditures over time (that is, on the basis of objective information). Thus, if Samuelson did indeed provide the first modern formulation of discounted utility theory, this was only as a joint product of another result. 
Samuelson's approach can be reconstituted on the basis of four propositions which he called "assumptions" (Samuelson, 1937, p. 157): ${ }^{5}$

I. The cardinality (or uniqueness) assumption (i.e. the existence of a utility function defined up to a positive affine transformation).

II. The assumption of commensurability of utilities, through the use of a discount rate.

III. The assumption of the integration in time of an income flow in order to determine intertemporal utility.

IV. The assumption of maximization under constraint, which leads to the complete specification of the utility function.

Each assumption is represented by what we can identify as a main equation. Together or separately, these main equations are related to complementary equations which act either as the conditions, the causes or the consequences of the main equations: ${ }^{6}$

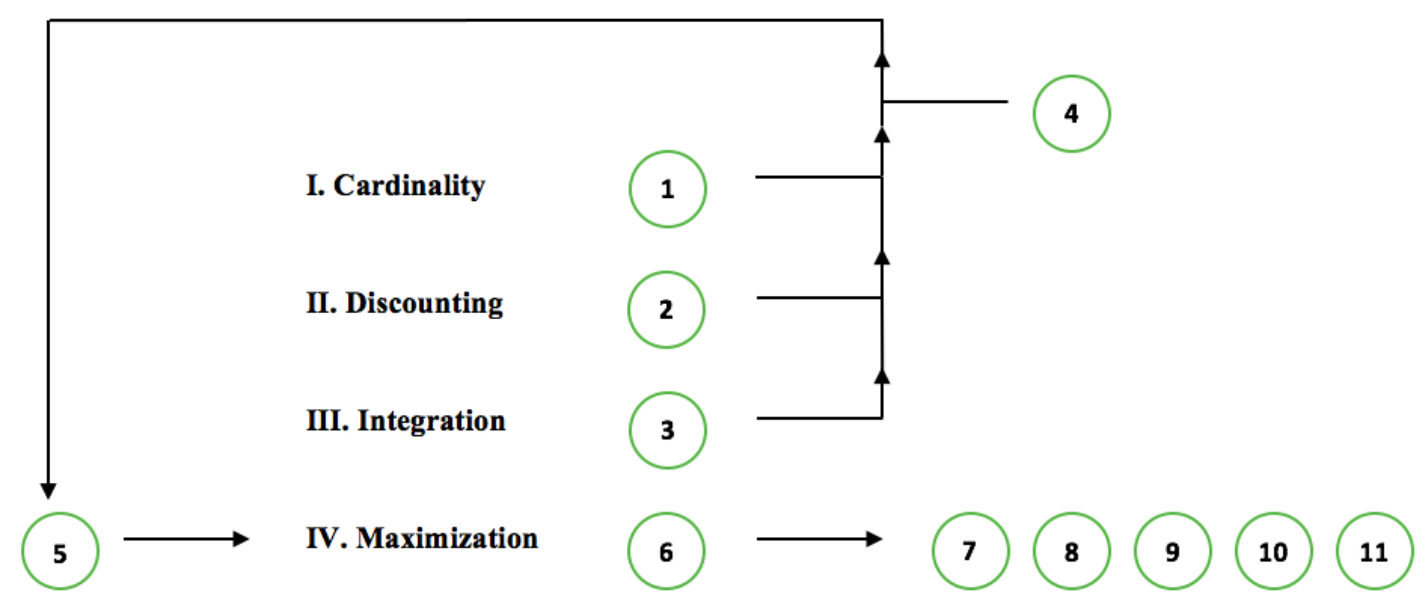

Figure 1: The structure of Samuelson's assumptions and set of equations

The outcome of this procedure to obtain cardinality is represented by the last equation (equation [7], see subsection 2.2), which provides the complete specification of the

${ }^{5}$ Samuelson used the term "assumption" to refer to both axioms and hypotheses, the difference being that axioms cannot be refuted by experience since all observable behaviours are likely to result from them, as opposed to hypotheses which can be refuted. For each "assumption", he clarified whether it should be regarded as an axiom or an hypothesis.

${ }^{6}$ The Roman numerals correspond to the numbering of the assumptions whereas the Arabic numerals correspond to the numbering of the equations below. 
cardinal utility function as depending on the time allocation of income, the discount rate of utility and the interest rate. The standard form of discounted utility only appears at an intermediate level, that of Assumption III, and is given by equation [3] (see subsection 2.2). The latter expresses the utility of a flow of income between two dates as the integral of the utility function weighted by an exponential discounting factor.

\subsection{Samuelson's procedure for obtaining a unique measure: the use of intertemporal choices}

The foregoing discussion of the purpose of the 1937 article is not sufficient, however, for us to grasp all that is at stake in it. Our concerns centre on (1) the difference between what Samuelson claimed he wanted to do in his 1937 paper and what we now understand from his words; and (2) identifying the analytical consequences that result from his method of measuring utility as applied to his qualified attitude towards cardinalism. These two points are dealt with in the remainder of this section and in the next.

\section{Cardinality (Assumption I)}

Relying on the definition given by Lange in 1934, Samuelson associated cardinality, the uniqueness of the measure, with the possibility of having a defined utility function $U$ up to all positive affine transformations of the form $W=f(U)=a U+b$ with $(a>0)$ (see infra. section 3). He therefore looked for a specific class of functions, in contrast to ordinal functions which allow all types of increasing monotonous transformations. The challenge was to determine the specific form of the utility function $U$ since the uniqueness of the measure of utility depends on it (Assumption 1 ). ${ }^{7}$ Assuming that prices and individuals' tastes are constant over time, changes in utility over time only result from changes in the flow of income $x$, which in turn depends on individuals' intertemporal distribution of income. It is the shape of this income distribution over time that will determine the form of the utility function, which is of the type: ${ }^{7}$ I have preserved Samuelson's notation, but adapted the symbols and numbering of the
equations. 


$$
U=U(x)
$$

Having the form of the utility function would imply that we know all the different "instantaneous satisfactions" (Samuelson, 1937, p. 159), that is, each utility $U$ of an income flow $x$ per unit of time. Note, however, that although $U(x)$ looks like any standard utility function, it has the specific character that $x$ is not a stock but a flow, that is, a quantity per unit of time.

\section{Discounting (Assumption II)}

An immediate consequence of this is that two questions arise. The first question is that of the relation between the utility of an income flow $x$ when it occurs at date $t$ and its present reflection as satisfaction. The second concerns the way in which these single present utilities echoing future instantaneous utilities might be related in order to give the total present utility. Samuelson's answer to these two questions amounts to considering this total present utility as a sum (answer to question 2) of the weighted associated instantaneous utilities (answer to question 1). For now, let's focus on the first question, the way the present utility $V(x, t)$ is derived from the utility of an income flow $x$ at date t. Samuelson's answer was (Assumption II):

$$
V(x, t)=U(x) e^{-\pi t}
$$

The weight of $U(x)$ is given by an exponential discount factor $e^{-\pi t}$ in which $\pi$ stands for the discount rate of future utilities.

We can link the fact that the discount factor is a decreasing value of time smaller than 1 (equal to 1 when $t=0$ ) to what is now called "impatience" in intertemporal decision theory (see axiom 3 in Fishburn and Rubinstein, 1982, p. 680). ${ }^{8}$ Impatience expresses the idea that the utility function $V$ is a decreasing function of time: the utility of 1000 euros in one year will be less than the utility of 1000 euros today. But the discount factor $e^{-\pi t}$ has another particular feature: it assumes that the discount rate $\pi$ is a constant. Along with the exponential form of the resulting discount factor, this refers to what we now define as the "stationarity" property in intertemporal decision theory (see axiom 5 in

\footnotetext{
${ }^{8}$ The axiom of impatience is formally presented as follows for all $x, y \in X$ and all $s, t \in T:$ if $s<t$ then $x>0 \Rightarrow(x, s)>(x, t)$ and $x=0 \Rightarrow(x, s) \sim(x, t)$. If $x$ is positive, we prefer to have it earlier (in $s$ ) than later (in $t$ ). If it is zero, the date is indifferent.
} 
Fishburn and Rubinstein, 1982, pp. 681-682). ${ }^{9}$ This property expresses the idea that if an individual is indifferent between two baskets of goods from different dates, this indifference is preserved whether they are distant or close in time. This means that if we are, for instance, indifferent between 1000 euros today and 1100 euros a year from now, we are also indifferent between 1000 euros five years from now and 1100 euros six years from now. Samuelson introduced this idea, which is a characteristic of the constant discount rate, not at the moment he presented equation [2] (see Samuelson, 1937, p. 156, equation (3)), but towards the end of his paper when he himself discussed the limitations of his work. It is at this point that he explained:

A less important point to be noted is the fact that our equations hold only for an individual who is deciding at the beginning of the period how he will allocate his expenditures over the period. [...] Contemplation of our particular equations will reveal that the results are unchanged even if the individual always discounts from the existing point of time rather than from the beginning of the period. He will still make at each instant the same decision with respect to expenditure as he would have, if at the beginning of the period he were to decide on his expenditure for the whole period. (Samuelson, 1937, p. 160)

A few decades before Tjalling C. Koopmans and Peter C. Fishburn and Ariel Rubinstein, Samuelson had introduced rationality to the analysis of decision over time: an individual is considered rational in his choices over time when stationarity is satisfied. Rationality here means avoiding time inconsistencies, since it preserves the order of preferences between two baskets of goods whether they are distant or close in time, provided the time distance between them remains the same. Samuelson's position was pioneering in that he understood that when exponential discounting utility prevails, we also have timeconsistency. We know today that the former is a necessary and sufficient condition of the latter.

\section{Integration (Assumption III)}

\footnotetext{
${ }^{9}$ The axiom of stationarity, on the other hand, is formally presented as follows for all $x, y \in X$ and all $t, s, t+\tau, s+\tau \in T$ : if $(x, t) \sim(y, t+\tau)$ then $(x, s) \sim(y, s+\tau)$. If $x$ and $y$ are indifferent on a date $t$ when they are separated by a time $\tau$, they are also indifferent on another date $s$ when they remain separated by $\tau$. Koopmans (1960, Postulate 4, pp. 294-295) already introduced stationarity in the context of sequences over time.
} 
Let us return to Samuelson's answer to the second question raised above, concerning the way the flow of discounted utilities gives rise to total intertemporal utility. The latter is obtained by summing all the discounted utilities $V(x, t)$ given by equation [2] or, in continuous time, ${ }^{10}$ by integrating them on $t$. Total intertemporal utility is given by (Assumption III): ${ }^{11}$

$$
J=\int_{0}^{b} U(x) e^{-\pi t} d t
$$

(where 0 and $b$ are the limits of the integration and $J$ is the discounted total utility at date 0 , that is, the total utility derived from the intertemporal allocation of the flow of income $x$ over the entire period from 0 to $b$ ).

An outstanding and nowadays well-known property of $U(x)$ relative to $J$ clearly appears from equation [3]. Consider two alternative trajectories of income flows and suppose that for a specific utility function $U$, the intertemporal utility generated by the first trajectory is greater than the one generated by the second. If $U$ were ordinal, it would be easy to find an increasing monotonous transformation which would reverse the relative magnitudes of utilities, so that after this transformation, the intertemporal utility of the second will seem greater than that of the first. To avoid this, the only possibility is for $U$ to be defined up to a positive affine transformation, which means that it is cardinal. Cardinality is

${ }^{10}$ It is not self-evident that the discrete-time and the continuous-time approaches would have given rise to similar result. Yet a contribution by Loewe (2006) reconstructs Samuelson's approach within a discrete time framework and reaches the same conclusions. More generally, it seems that Samuelson's adoption of a continuous time approach is an effect of his ambition to build a more general theory of human interactions (on this last point, see Backhouse, 2017, p. 113).

${ }^{11}$ The cognitive process on which the model was built is made at least partially explicit by Samuelson himself in the conclusion of his paper, where he writes that "[o]ur task now is to indicate briefly the serious limitations of the previous kind of analysis, which almost certainly vitiate it even from a theoretical point of view. In the first place, it is completely arbitrary to assume that the individual behaves so as to maximize an integral of the form envisaged in (3) [my notation]. This involves the assumption that at every instant of time the individual's satisfaction depends only upon the consumption at that time, and that, furthermore, the individual tries to maximize the sum of instantaneous satisfactions reduced to some comparable base by time discount" (Samuelson, 1937, p. 159). This means that, according to the model, $V$ and $J$ could be appropriate representations of what an agent has in mind. However, according to the qualification introduced by Samuelson, these are rather the representations that the economist has in mind. Thus the question of whether it is a reliable representation of what the agent has in mind remains open, according to Samuelson himself. 
therefore not only a contingent assumption about the specification of $U(x)$ in Assumption I, but also a requirement of the construction itself.

The additive way of constructing intertemporal utility therefore plays an important part. But it could be approached differently. Note that in equation [3], the utility function $U$ is not time-dependent. Similarly, the discount rate $\pi$ is also independent of time, which leads to the conclusion that only the discount factor $e^{-\pi t}$ incorporates the individuals' time preferences. The discount factor thus appears as "independent (separate) from utility" (Loewe, 2006, p. 201). The additively separable structure of intertemporal utility is strongly linked to the idea that we do not have preferences that would make the utility of a good $x_{1}$ at a date $t_{1}$ dependent on the availability of another good $x_{2}$ at a date $t_{2}$. For instance, I may differently value my first dish, at the beginning of the dinner, depending on whether I have a second dish. Separability excludes what Robert Strotz (1955, p. 165) called "calendar" preferences. Now, when calendar preferences are excluded, there is no kind of complementarity in time between consumptions at different points in time. Samuelson (1937, p. 156) was clearly aware of the scope and importance of this assumption of additivity, assigning it the status of an axiom: impossible to refute. Today, such a methodological position would hardly be sustainable: one could test the additive separability of an intertemporal utility function by testing the lack of complementarity between choices over time. But through the alleged absence of the calendar preferences, we come to another way of understanding the necessity of a cardinal representation of $U$ : if we agree with the principle of an absence of complementarities in time (i.e. no calendar preferences), we have a justification for additivity and, therefore, again, for cardinality.

\section{Maximization (Assumption IV)}

The last assumption required in order to obtain the form of the utility function is motivational: individuals are supposed to maximize their total intertemporal utility under a budget constraint (Assumption IV). This is equivalent to solving the usual optimization program of consumer theory, which is transposed here to the field of decision-making over time: the budget constraint results from an amount of income $S$ that individuals receive at the beginning of the period and that they distribute throughout it. Unspent income earns interest at any future date at a rate $r$. The budget constraint is of the type: 


$$
S=\int_{0}^{b} x(t) e^{-r t} d t
$$

By maximizing the objective function given by equation [3] under the budget constraint given by equation [4], we obtain the following expression of the marginal utility, immediately derived from the first-order conditions for a maximum:

$$
U^{\prime}(x)=\lambda e^{(\pi-r) t}
$$

(where $\lambda$, the Lagrange multiplier, is interpreted as a constant that standardizes the unit of measurement of utility with respect to the level of $S$ ).

Equation [5] thus provides the expression of the marginal utility of an income flow $\left(U^{\prime}(x)\right)$. To obtain a time-independent expression of marginal utility, Samuelson relied on the fact that we know the shape of the income distribution of individuals over time. From this observed distribution, he inferred an application $q$ from the income $x$ to the date $t$ when it is distributed (see Samuelson, 1937, p. 158). Thus equation [5] can be rewritten:

$$
U^{\prime}(x)=\lambda e^{(\pi-r) q(x)}
$$

Finally, by integration, Samuelson came to the form of the utility function and its timeindependent expression:

$$
U(x)=\lambda \int_{C} e^{(\pi-r) q(x)} d x
$$

(where $C$ indicates the limits of the integration).

The originality of Samuelson's procedure for obtaining the form of the utility function is revealed by this last step: $U(x)$, which is not defined on dated variables, is derived from an observed intertemporal distribution of income, without carrying the temporal elements that generate this distribution. It seems clear, therefore, that his main objective was to provide the conditions for achieving measurability of utility (in the sense of what we call today an "interval scale" (see Stevens, 1946), i.e. cardinality). So that, whereas he did lay the foundation of discounted utility theory, this was only a by-product of the whole procedure. His methodological approach of expressing the utility function by something distinct from it would be taken up again a year later in the article that led to the development of revealed preference theory (Samuelson, 1938a). As in Samuelson 1938a, in which preferences are revealed by choices, in the 1937 article the form of the utility 
function is revealed by the intertemporal allocation of income. Similarly, and again like his $1938 \mathrm{a}$ in which he introduced the weak axiom of revealed preferences as a principle of consistency regarding choices, in the 1937 article Samuelson introduced the discounting and integration assumptions on which the function to be maximized is built.

\section{The unique measure of utility: cardinalism compelled}

Let us take as a starting point for this section Samuelson's own remark on the last page of his paper, concerning its limitations:

Our task now is to indicate briefly the serious limitations of the previous kind of analysis, which almost certainly vitiate it even from a theoretical point of view. (Samuelson, 1937, p. 159)

It is here he raises the important question of how he had succeeded in giving more than, in his words, an "index of utility":

In what way have our assumptions enabled us to arrive at a particular measure of utility rather than merely one index of utility? Reflection as to the meaning of our Assumption Two, that the individual seeks to maximize an integral of the kind envisaged in (2) [see subsection 2.2, equation [3]] will reveal that the individual must make preferences in the Utility dimension itself, that is to say, we must invoke Pareto's Postulate Two, which relates to the possibility of ordering differences in utility by the individual. ${ }^{[12]}$ The advantage of our experiment is that it compels the individual to make just such judgments. Thus, with postulates one and two being fulfilled, it is to be expected that utility is uniquely measurable. (Samuelson, 1937, pp. 160-161)

\footnotetext{
${ }^{12}$ As Samuelson acknowledged, Vilfredo Pareto (1906) tried to give conditions for both an ordinal and a cardinal approach to utility. Pareto ([1906] 2014, p. 132) introduced a discussion of the possibility of a cardinal measure of utility in $\S 32$ of his Manual of Political Economy devoted to "ophelimity and its indices". According to a first assumption, the economic agent would be able to know whether the utility derived from one combination of goods is greater, equal to, or less than the utility derived from another combination of goods. This corresponds to an ordinalist view of utility and gives rise to what is, at least since Stanley S. Stevens (1946), considered as an ordinal measure of utility. But according to a second assumption, the economic agent would also be able to know whether the change in utility due to a change from one combination of goods to another is greater than, equal to, or less than the change in utility due to a change from this second combination to a third. This means that the economic agent would be in a position to judge which movement brings him the greatest gain in utility. The addition of the second assumption thus seems to allow a shift from an ordinal to a cardinal measure of utility (here again, see Stevens, 1946).
} 
Samuelson's answer in this quotation reveals his opinion on what the agents actually know: they know what is needed to build indices of utility, and that's all. This means that regardless of time, even if in the mind of the agents there is something which could be represented by a cardinal utility function, we only have access to an ordinal function of utility. And, in most cases, this is consistent with what we need to account for standard problems of consumer theory. In passing, note that this is consistent with what we know of Samuelson's ordinalist position as he set it out in later works. Going beyond ordinality requires that the individual do something that is not in fact so easy: he must be placed in a special situation, that of an experiment like the one described by Samuelson, where he must make a decision over time. This type of decision is one that compels him to make introspective comparisons that turn out to be equivalent, structurally, to what is required to obtain a cardinal utility, which in turn is maximized (see subsection 2.2, equation [3]). It seems all the more obvious that the cardinality assumption is something which the agent is obliged to adopt, and which rests on an underlying cognitive ability, given that Samuelson himself insisted on the difficulty, or rather the arbitrariness, of satisfying the conditions required for cardinality:

In the first place, it is completely arbitrary to assume that the individual behaves so as to maximise an integral of the form envisaged in (2). (Samuelson, 1937, p. 159)

\subsection{How to cardinalize?}

Viewed from the present day, Samuelson's vocabulary is a bit puzzling. What he says about an index of utility refers to an ordinal representation. Using a different vocabulary from that of Samuelson, we speak of an ordinal representation of utility when a function of utility $U$ represents a binary relation $R$ between two combinations of goods. Allowing that $R$ is complete and transitive and is, for instance, either countable or continuous on $X$, we know that there exists a $U$ that represents $R$, allowing an ordinal measurement. In an ordinalist perspective, larger figures are assigned to choices that provide the agent with greater utility. But nothing else can be inferred on the basis of these figures: "utility" is a simple mathematical tool that reveals an unknown and presumably mental process. This tool is only present in the minds of the economists who use it to represent an agent's preferences. Since these indices of utility can be replaced by any other set of indices representing the preferences (that is, if we can substitute for a utility function $U$ a function 
$\left.V=g(U)\left(g^{\prime}(U)>0\right)\right)$, such a measure is not seen as "unique". Indeed, according to Stevens's (1946) theory of measurement, an ordinal measure would correspond to an ordinal scale, for which the same preferences can be represented by different functions related to each other by an increasing monotonous transformation. Stated differently, it is well known that the ordinal measure might be viewed as a representation of a complete weak order of preferences $R$, such that $x R y$ is equivalent to $U(x) \geq U(y)$. It is also well known that if $U$ satisfies this equivalence, this is also the case for every $V$ such that $V=$ $g(U)\left(g^{\prime}(U)>0\right)$. Thus, referring to ordinal measures means referring to this set of ordinal functions.

By contrast, we speak of a cardinal representation of utility when the utility function $U$ is also invariant regarding differences in utility: it reveals the change in utility due to a change from one combination of goods to another compared to a change from this second combination to a third. Such invariance has consequences on the resulting measures: $U$ now allows for cardinal measurement. This time, differences between utilities become meaningful, so that the utility function can no longer be replaced by any alternative utility function that would simply represent preferences. This measure is now interpreted as being unique: according to Stevens's (1946) theory of measurement, cardinality, i.e. unique measures, would refer to the interval scale or, in the case where the zero is significant, to the ratio scale. Uniqueness amounts to picking a specific subset of functions within the set of ordinal functions. ${ }^{13}$ This new subset also contains the acceptable utility functions, but they are now related by positive affine transformations: possible substitutes for $U$ are some (or all; this is a matter of discussion) $W=f(U)=$ $a U+b(a>0), b$ being equal to zero in the case of a ratio scale. It is clear that the first derivative of $f$ is positive, so that all possible $f(U)$ belonging to $W$ also belong to $V$. Cardinality therefore rests on more restrictive conditions. This means that from any function representing the preferences of the agent, it is possible through positive affine transformation to derive a subset of functions representing his preferences and judgments. Potentially, all the functions of the initial set can be the starting point of the subset of

\footnotetext{
${ }^{13}$ A similar approach was introduced by Chipman (1977) when he argued that increasing monotonous transformations were a too large class of transformations to preserve the sign of the cross derivatives of the utility function.
} 
positive affine transformations. But once a function has been chosen (arbitrarily or by experiment), it is necessary to find the specific statements that would be verified with any positive affine transformation but not with other types of positive transformations: one could then say that the agent's capacity to make certain comparisons induces these statements relative to transitions and not only to levels of utility. As opposed to an ordinal measurement, cardinality implicitly credits the agents with cognitive abilities: it treats utility as something that is actually in the heads of agents and that they use to make their choices. Utility is no longer only a representation of preferences; it also has a meaning in itself. The switch from one function to another that is linearly related can be viewed as a change in our instrument of measure. But all these measures are equivalent, since they refer to the same preferences and to the same statements about comparisons. It is in this sense that we can understand Samuelson's vocabulary when he spoke of a "unique" measure (Samuelson, 1937, p. 156). He was quite explicit about the way to obtain such a unique measure:

Later from the actual observable shape of the income expenditure as a function of time, we shall be able to deduce the actual shape of the utility function, invariant except for a linear transformation, i.e. scale and origin constants. (Samuelson, 1937, p. 157)

A contemporary reader might be puzzled by the vocabulary used in the 1930s, where Lange or Samuelson speak of a unique measure of utility up to a "linear transformation". A hasty reading might be misleading, since the phrase suggests a ratio-scale transformation of the type $f(U)=a U(a>0)$. However, this is not what Samuelson meant. Three arguments contribute to clarifying this issue: (1) he used the same phrasing in his 1938 b (p. 66) article where he explicitly associated the "linear transformation" with the mathematical expression $f(U)=a U+b(a>0)$; (2) he claimed that scale $(a$, in the previous expression) and origin (b) are constants (Samuelson, 1937, p. 157); and (3) he $(1937$, p. 161) referred to Lange (1934, p. 221) who himself spoke of a "linear transformation" to designate a "positive affine transformation". All this shows that what Samuelson had in mind is what we call today a positive affine transformation, associated with measurement on an interval scale - and not, specifically, a ratio scale.

It is thus within this framework that the question of the uniqueness of the measure comes into play in Samuelson's 1937 paper. But in this measurement operation the specification of the form of the utility function depends on how the utilities are discounted 
over time, i.e. on $\pi$, which Samuelson claimed "in the first instance" to be a constant, as a means of simplification:

The individual discounts future utilities in some simple regular fashion which is known to us. For simplicity, we assume in the first instance that the rate of discount of future utilities is a constant. [...] Moreover, this assumption, added to the previous ones, serves to limit our marginal utility function to a sub-class of all possible functions, from which sub-class it will be possible to identify a unique utility function. (Samuelson, 1937, p. 156)

\subsection{The legacy of decision over time}

It is true that with the introduction of $\pi$, a timeless perspective is transformed into an intertemporal approach. The difficulty is that the reader, after learning that $\pi$ is constant in the first instance, may never find the second instance, since all Samuelson says is that it can be determined experimentally:

This suggests a possible way to determine experimentally the value of $\pi$, i.e. by determining for which value of $r$ the rate of money expenditure is a constant. (Samuelson, 1937, pp. 158-159)

What then would be the consequences, in Samuelson's framework, of a change in the discount rate? The way he builds his argument also helps us find the answer. Utility is given first. This means that the cardinal utility we are compelled to have as agents preexists the discount rate (see subsection 2.2, equations [1] and [2]).

It is important to emphasize the meaning of such a proposition. It means that if $U$ is cardinal, this is due to its own nature and because of our cognitive ability to cardinalize, and not because it is cardinalized by decision in time, since the kind of cardinalization required by decision in time has nothing to do with the variations in utility we could feel independently of the intertemporal context. The change in $\pi$ would therefore only result in a change in the present values of future utilities, that is, in a change in $V$ (see subsection 2.2, equation [2]), not in a change in $U$.

Samuelson's approach in 1937 might be compared with the modern approach resulting from Fishburn and Rubinstein's 1982 paper. Theorem 2 from Fishburn and Rubinstein (1982, p. 682) leads them to conclude that weakly ordered complete preferences over time can be represented by any element of a class of pairs $(\pi, U)$ in which $U$ is also a cardinal function of utility, that is, defined up to a positive affine 
transformation. This means that when $\pi$ is changed to $\pi^{\prime}, U$ should also change to $U^{\prime}$, which is not a positive affine transformation of $U$. This result shows that, without more detail, the discount rate alone cannot be considered as expressing something like a preference for the present (since many values of $\pi$ are consistent with the same preferences over time). And symmetrically, $U$ cannot be considered as cardinal utility expressing only desirability without any concern for time. The usual way to deal with Fishburn and Rubinstein's result is to consider that $\pi$ is given, because it is, for instance, equal to the interest rate, and then to select the utility function consistent with it. But if so, although this is a way to pick out a cardinal measure of utility, it is difficult to interpret it in the usual direct sense of desirability regardless of time. Despite the cardinal form of the utility function, we are faced with the same kind of issue as with expected utility: the form of the function expresses an attitude towards the present, just as with expected utility it expresses an attitude towards risk. And in both cases, it cannot be interpreted simply as an expression of the intensity of desirability independent of time or risk. By contrast, Samuelson described a procedure in which we are compelled to build a cardinal measure of utility. Cardinality is compelled by the experiment itself: it is only through experimentation that we can reveal the way we discount utilities and so determine the shape of our own utility function. Unlike Fishburn and Rubinstein, such cardinality is directly meaningful in terms of time-independent desirability intensity, not as a property of a function that, associated with $\pi$, would reflect time preferences. Hence a change in the rate of discount $\pi$, though a change in time preferences (influencing $V$ ), is not a change in our instantaneous utility function $U$. This change in $\pi$ will obviously modify the way we allocate income through time. But this new allocation preserves the utility function which is constructed independently of time.

\section{Conclusion}

This paper has led to two results concerning Samuelson's 1937 article. The first is that his treatment of discounted utility is a by-product of his obtaining a unique - that is, cardinal - measure of utility. The uniqueness of the utility measure was indeed a central topic of research in the 1930s, interpreted as the possibility of finding a cardinal measure, or in other words as the possibility of representing the same preferences by a unique utility 
function. This was a matter of identifying a specific subset of functions within a set of ordinal functions. And since this new subset also contains many acceptable utility functions, they are now linked by positive affine transformations (which has defined cardinality since Lange, 1934). According to Samuelson, writers such as Fisher (1927) and Frisch (1932) (the only authors he cites (Samuelson, 1937, p. 155, n. 1)), who had attempted to measure the marginal utility of income in a unique way, only managed to reach indices of utility. They only provided a method for the construction of the indifference curves, which amounts to having an ordinal measure. It was therefore in order to obtain, on the contrary, a unique measure of utility that Samuelson imagined variations of income over time. His procedure is particularly skilful in that cardinality is achieved on the basis of experimental data: variations in income impose an additional constraint on the form of the utility function, making it cardinal. Although it was not his primary purpose, Samuelson's paper did provide what is now considered to be the standard theory of decision over time, the so-called discounted utility theory.

The second result concerns Samuelson's position on cardinality. Beyond its impact on the formal procedure leading to the determination of cardinal utility, the discounted utility analysis may also have influenced, among other things, Samuelson's understanding of cardinality itself. Whereas Samuelson defined cardinality in the usual sense (Lange, 1934), he saw it as an arbitrary assumption about the behaviour of agents. He argued that the knowledge of the specific form of the utility function requires the elaboration of an experimental procedure in which the agents are compelled to be cardinal. Cardinality is therefore the result of a cognitive ability that manifests itself in the context of a decision experiment over time. ${ }^{14}$ The question is not whether we are cardinal or not when we have only to take instantaneous decisions: it is only decision in time which might force us to reveal some cardinality.

The outstanding point is that these two outcomes are intertwined: they make sense only when taken together. Samuelson's reservations on cardinalism are only intelligible

\footnotetext{
${ }^{14}$ Note that in an article on cardinality published the following year (the same year as his paper on revealed preferences), Samuelson also considered cardinality as a separate cognitive ability of agents, this time linked to the specific capacity to order differences, that is to say, transitions from one situation to another (Samuelson 1938b).
} 
on the basis of a time-decision-theoretic approach to measuring utility. It is because of the time procedure that we can obtain the specific form of the utility function, i.e. cardinality - since the different future utilities must be integrated to express the resulting total intertemporal utility from which the form of the utility function can be deduced. If time were not to be taken into account, cardinalism would no longer be necessary to express the utility function and ordinalism would be sufficient: we only have cardinality relative to a time-perspective approach, without which there is no reason to assume it. And, finally, we may note that Samuelson's conclusion confirms the limited scope of his cardinalism. Contrary to a common view, then, we have no reason to infer that there was a change in Samuelson's position after 1937. His own doubts about the cognitive basis of the avowedly limited procedure he had constructed shows that his position was already ordinalist, and that this position was not seriously threatened by the outcome of his 1937 paper.

\section{Acknowledgements}

This paper owes a lot to the comments and suggestions of André Lapidus, to whom I would like to express my warmest thanks. I am especially grateful to Herrade Igersheim for her valuable comments. I would also like to thank Ben Young for his careful reading, and the two anonymous referees of this Journal for their insightful suggestions. Nonetheless, the usual caveat holds.

\section{References}

Alchian, Armen A. (1953). The Meaning of Utility Measurement, The American Economic Review, 43(1), pp. 26-50.

Allen, Roy G. D. (1935). A Note on the Determinateness of the Utility Function, Review of Economic Studies, 2(2), pp. 155-158.

Alt, Franz ([1936] 1971). On the Measurability of Utility, in J. S. Chipman et al. (Eds.), Preference, Utility and Demand, New York: Harcourt Brace Jovanovich, pp. 424431.

Backhouse, Roger E. (2017). Founder of Modern Economics: Paul A. Samuelson, Volume I: Becoming Samuelson, 1915-1948, New York: Oxford University Press. 
Bernardelli, Harro (1934). Notes on the Determinateness of the Utility Function: II, Review of Economic Studies, 2(1), pp. 69-75.

Chipman, John S. (1977). An Empirical Implication of Auspitz-Lieben-EdgeworthPareto Complementarity, Journal of Economic Theory, 14, pp. 228-231.

Ellingsen, Tore (1994). Cardinal Utility: A History of Hedonimetry, in M. Allais and O. Hagen (eds.), Cardinalism, Kluwer Academic Publishers, pp. 105-165.

Ellsberg, Daniel (1954). Classic and Current Notions of "Measurable Utility", The Economic Journal, 64(255), pp. 528-556.

Fishburn, Peter C. and Rubinstein, Ariel (1982). Time Preference, International Economic Review, 23(3), pp. 677-694.

Fisher, Irving (1927). A Statistical Method for Measuring "Marginal Utility" and Testing the Justice of a Progressive Income Tax, in J. H. Hollander (ed.), Economic Essays Contributed in Honor of John Bates Clark, New York: Macmillan.

Frederick, Shane, Loewenstein, George \& O’Donoghue, Ted (2002). Time Discounting and Time Preference: A Critical Review, Journal of Economic Literature, 40(2), pp. 351-401.

Frisch, Ragnar (1932). New Methods of Measuring Marginal Utility, Tübingen: Verlag von J. C. B. Mohr (Paul Siebeck).

Hicks, John and Allen, Roy G. D. (1934). A Reconsideration of the Theory of Value. Part I and II, Economica, 1(1), pp. 52-76, 1(2), pp. 196-219.

Hudik, Marek (2014). Reference-Dependence and Marginal Utility: Alt, Samuelson, and Bernardelli, History of Political Economy, 46(4), pp. 677-693.

Koopmans, Tjalling C. (1960). Stationary Ordinal Utility and Impatience, Econometrica, 28(2), pp. 287-309

Lange, Oskar (1934). The Determinateness of the Utility Function, Review of Economic Studies, 1(3), pp. 218-225.

Loewe, German (2006). The Development of a Theory of Rational Intertemporal Choice, Revista de Sociologia, 80, pp. 195-221.

Loewenstein, George and Prelec, Drazen (1992). Anomalies in Intertemporal Choice: Evidence and an Interpretation, Quarterly Journal of Economics, 107(2), pp. 573597.

Manzini, Paola and Mariotti, Marco (2009). Choice over time, in Anand, Paul, Pattanaik, Prastanta K., and Puppe, Clemens (eds.), Handbook of Rational and Social Choice, Oxford, New York: Oxford University Press, pp. 239-270.

Moscati, Ivan (2013). How Cardinal Utility Entered Economic Analysis, 1909-1944, European Journal of the History of Economic Thought, 20(6), pp. 906-939.

Moscati, Ivan (2019). From the Marginal Revolution to Behavioral Economics, New York: Oxford University Press.

Pareto, Vilfredo ([1906]2014). Manual of Political Economy, A critical and Variorum Edition [trad. angl.], edited by A. Montesano, A. Zanni, L. Bruni, J. S. Chipman and M. McLure, Oxford: Oxford University Press. 
Phelps Brown, Ernest H. (1934). Notes on the Determinateness of the Utility Function: I, Review of Economic Studies, 2(1), pp. 66-69.

Samuelson, Paul A. (1937). A Note on Measurement of Utility, Review of Economic Studies, 4(2), pp. 155-161.

Samuelson, Paul A. (1938a). A Note on the Pure Theory of Consumer's Behaviour, Economica, 5(17), pp. 61-71.

Samuelson, Paul A. (1938b). The Numerical Representation of Ordered Classifications and the Concept of Utility, Review of Economic Studies, (6)1, pp. 65-70.

Shefrin, Hersh (1998). Changing utility functions, in Barberà, Salvador, Hammond, Peter J. and Seidl, Christian (eds), Handbook of Utility Theory, vol. 1, Dordrecht: Kluwer Academic Press. 1998, pp. 569-626.

Stevens, Stanley S. (1946). On the Theory of Scales of Measurement, Science, 103(2684), pp. 677-680.

Strotz, Robert H. (1955). Myopia and Inconsistency in Dynamic Utility Maximization, Review of Economic Studies, 23(3), pp. 165-180.

Vickrey, William (1945). Measuring Marginal Utility by Reactions to Risk, Econometrica, 13(4), pp. 319-333.

Zeuthen, Frederik (1937). On the Determinateness of the Utility Function, Review of Economic Studies, 4(3), pp. 236-239. 